\title{
The influence of the stratosphere on the tropospheric zonal wind response to $\mathrm{CO}_{2}$ doubling
}

\author{
Y. B. L. Hinssen ${ }^{1, *}$, C. J. Bell ${ }^{2, \dagger}$, and P. C. Siegmund ${ }^{3}$ \\ ${ }^{1}$ Institute for Marine and Atmospheric research Utrecht, Utrecht University, The Netherlands \\ ${ }^{2}$ Department of Meteorology, University of Reading, UK \\ ${ }^{3}$ Royal Netherlands Meteorological Institute - KNMI, De Bilt, The Netherlands \\ * current address: Meteo Consult bv, P.O. Box 617, 6700 AP Wageningen, The Netherlands \\ $\dagger$ deceased, June 2010 \\ Received: 11 August 2010 - Published in Atmos. Chem. Phys. Discuss.: 12 October 2010 \\ Revised: 5 May 2011 - Accepted: 16 May 2011 - Published: 26 May 2011
}

Abstract. The influence of a $\mathrm{CO}_{2}$ doubling on the stratospheric potential vorticity (PV) is examined in two climate models. Subsequently, the influence of changes in the stratosphere on the tropospheric zonal wind response is investigated, by inverting the stratospheric PV.

Radiative effects seem to dominate the stratospheric response to $\mathrm{CO}_{2}$ doubling in the Southern Hemisphere. These lead to a stratospheric PV increase at the edge of the polar vortex, resulting in an increased westerly influence of the stratosphere on the troposphere, increasing the midlatitude tropospheric westerlies in late winter.

In the Northern Hemisphere, dynamical effects are also important. Both models show a reduced polar PV and an enhanced midlatitude PV in the Northern Hemisphere winter stratosphere. These PV changes are likely related to an enhanced wave forcing of the winter stratosphere, as measured by an increase in the $100 \mathrm{hPa}$ eddy heat flux, and result in a reduced westerly influence of the stratosphere on the high latitude tropospheric winds. In one model, the high latitude PV decreases are, however, restricted to higher altitudes, and the tropospheric response due to the stratospheric changes is dominated by an increased westerly influence in the midlatitudes, related to the increase in midlatitude PV in the lower stratosphere.

The tropospheric response in zonal wind due to the stratospheric PV changes is of the order of 0.5 to $1 \mathrm{~m} \mathrm{~s}^{-1}$. The total tropospheric response has a somewhat different spatial structure, but is of similar magnitude. This indicates that the stratospheric influence is of importance in modifying the tropospheric zonal wind response to $\mathrm{CO}_{2}$ doubling.

Correspondence to: Y. B. L. Hinssen

(yvonne.hinssen@gmail.com)

\section{Introduction}

Numerous studies have examined model simulations of climate change due to increasing greenhouse gas concentrations. In general, a warming of the troposphere and a cooling of the stratosphere are observed in these simulations (e.g., Gillett et al., 2003; Sigmond et al., 2004; Bell et al., 2010). The response in the zonal wind, however, reflects the changes in the horizontal temperature gradient, which shows more variability among models. Cooling in the polar lower stratosphere and warming in the tropical upper troposphere enhances the horizontal temperature gradient near the midlatitude tropopause. Through the thermal wind relationship, this is related to an increased vertical gradient of the wind in the midlatitude tropopause region possibly also affecting the tropospheric winds. There are indeed model studies that predict an increase in the Arctic Oscillation (AO) index, which is a measure for the tropospheric westerly flow at midlatitudes, for increasing greenhouse gas concentrations (Shindell et al., 1999; Gillett et al., 2002; Moritz et al., 2002). However, Baldwin et al. (2007) note that most climate models with a well-represented stratosphere indicate that the meridional overturning circulation in the stratosphere, the BrewerDobson circulation, will accelerate under climate change. This would lead to adiabatic warming and higher temperatures in the Arctic lower stratosphere, resulting in weaker westerly winds in the Northern Hemisphere extratropics. Although the exact future response of the AO index is still uncertain, it is likely that stratospheric processes play a role in forming the tropospheric response to climate change.

Sigmond et al. (2004) performed simulations with a global climate model in which the carbon dioxide $\left(\mathrm{CO}_{2}\right)$ concentration was separately doubled in the stratosphere, the troposphere, and the entire atmosphere. They found that the $\mathrm{CO}_{2}$ doubling in the entire atmosphere leads to an increase of the

Published by Copernicus Publications on behalf of the European Geosciences Union. 
tropospheric midlatitude westerlies in the Northern Hemisphere winter, and that this increase in the troposphere is mainly due to the $\mathrm{CO}_{2}$ doubling in the stratosphere. There are two ways by which stratospheric climate change due to increased $\mathrm{CO}_{2}$ can have an effect on the troposphere, namely the effect of stratospheric $\mathrm{CO}_{2}$ increase on the troposphere, and the effect of stratospheric climate changes, due to tropospheric $\mathrm{CO}_{2}$ increase, on the troposphere. Only the former effect was investigated by Sigmond et al. (2004). However, they also find that $\mathrm{CO}_{2}$ doubling in the troposphere leads to an enhanced Brewer-Dobson circulation in the stratosphere and warming of the polar lower stratosphere in northern winter. It is not yet known how this troposphere-induced stratospheric change affects the troposphere. This question is considered in the present study. More specifically, we investigate the effect of stratospheric climate change due to $\mathrm{CO}_{2}$ increase in the entire atmosphere on the tropospheric wind, by applying piecewise potential vorticity (PV) inversion on the stratospheric $\mathrm{PV}$ in a reference climatology and the stratospheric $\mathrm{PV}$ in a doubled $\mathrm{CO}_{2}$ climatology.

This work is based on simulations with the middleatmosphere version of the ECHAM4 climate model as performed by Sigmond et al. (2004) and simulations with the 64-level version of the Hadley Centre Atmosphere Model coupled to a thermodynamic slab ocean model (HadSM3), which is based on the Unified Model (Gillett et al., 2003; Bell et al., 2010). These models will be referred to as the "ECHAM model" and the "UM model", respectively. For both models, results from a control run and a run with doubled carbon dioxide concentrations are used. The studies of Sigmond et al. (2004) and Gillett et al. (2003) describe the effect of $\mathrm{CO}_{2}$ doubling in terms of temperature and wind changes. Bell et al. (2010) further show that the doubled $\mathrm{CO}_{2}$ response in the UM model is robust, as a similar structure of the response, but with larger amplitude, is found under quadrupled $\mathrm{CO}_{2}$ concentrations. Here we focus on changes in the stratospheric $\mathrm{PV}$ that are related to $\mathrm{CO}_{2}$ doubling, and investigate to what extent these stratospheric changes influence the tropospheric zonal mean zonal wind response.

Piecewise PV inversion (Davis, 1992) is used on a monthly basis to examine to what extent the zonal mean influence of the stratosphere on the tropospheric winds changes due to an increase in greenhouse gases. PV inversion makes use of the relation between the PV and other dynamical fields, that is given by the invertibility principle (Kleinschmidt, 1950; Hoskins et al., 1985). Previous PV inversion studies (e.g., Hartley et al., 1998; Black, 2002; Black and McDaniel, 2004; Hinssen et al., 2010) showed that changes in the lower stratospheric PV influence the winds in the troposphere. The fact that a balanced response to a stratospheric forcing can affect the troposphere is used in PV inversion studies like the ones mentioned above as well as in downward control calculations (Haynes et al., 1991; Haynes, 2005; Thompson et al., 2006) A change in the stratospheric PV due to an increase in $\mathrm{CO}_{2}$ might therefore affect the tropospheric wind.
Section 2 presents an overview of the data used and a short description of the PV inversion method. The influence of a $\mathrm{CO}_{2}$ doubling on the stratospheric PV is presented in Sect. 3, while the influence of the stratosphere on the tropospheric zonal wind response is studied in Sect. 4. Finally, some conclusions are given in Sect. 5.

\section{Data and inversion method}

The climatological PV is determined from the monthly mean temperature and zonal mean wind on 30 pressure levels between $1000 \mathrm{hPa}$ and $0.01 \mathrm{hPa}$ for the UM model, where a 25-yr control run (pre-industrial $\mathrm{CO}_{2}$ concentration of $289 \mathrm{ppmv}$ ) and a $25-\mathrm{yr}$ doubled $\mathrm{CO}_{2}$ run are considered (Gillett et al., 2003). A zonal mean reconstruction of preindustrial ozone concentrations was prescribed, and the $\mathrm{CO}_{2}$ concentrations were kept constant within a run. The monthly mean data of the zonal wind and the temperature are interpolated from isobaric to isentropic levels with the method described by Edouard et al. (1997). Zonal averaging and averaging over the 25 years is performed to obtain a climatological dataset of the zonal mean zonal wind and pressure on isentropic levels. In order to make optimal use of the data, a stretched grid in the vertical direction is employed. The zonal mean isentropic potential vorticity $Z_{\theta}$ (Hoskins et al., $1985)$ is then calculated from:

$Z_{\theta}=\frac{\zeta_{\theta}+f}{\sigma}$

Here $\zeta_{\theta}$ is the zonal mean isentropic relative vorticity, $f$ is the Coriolis parameter and $\sigma$ is the isentropic density:

$\zeta_{\theta}=-\frac{1}{a} \frac{\partial u}{\partial \phi}+\frac{u \tan \phi}{a}$

$\sigma=-\frac{1}{g} \frac{\partial p}{\partial \theta}$

Here $u$ is the zonal mean zonal wind, $\theta$ is the potential temperature, $a$ is the radius of the Earth, $\phi$ is the latitude, $p$ is the pressure and $g$ is the gravitational acceleration. This gives a climatological dataset of zonal mean PV, zonal wind and pressure on isentropic levels. The domain of this dataset ranges from $90^{\circ}$ to $10^{\circ}$ north and south (the tropical band is excluded, since the PV can occasionally be negative (positive) between the equator and $10^{\circ} \mathrm{N}\left(10^{\circ} \mathrm{S}\right)$ and the PV inversion equation described below is not solvable then), with a horizontal resolution of $2.5^{\circ}$, and from the lower troposphere to about $1250 \mathrm{~K}$ in the vertical, with a resolution varying from about $2 \mathrm{~K}$ in the troposphere to $10 \mathrm{~K}$ in the upper layers. The lower boundary for each latitude is defined as the lowest isentropic level for which data is available along the full latitude circle (meaning that the pressure is below $1000 \mathrm{hPa}$ at all longitudes along this latitude circle). We will refer to this lower boundary as the "surface", but it should be noted that 
this does not correspond to the actual surface of the Earth, but is located in the lower or middle troposphere.

Similarly, the climatological PV is determined from the monthly mean temperature and zonal mean wind on 33 pressure levels between $1000 \mathrm{hPa}$ and $0.01 \mathrm{hPa}$ for the ECHAM model, where the last 20 years of both the control run $\left(\mathrm{CO}_{2}\right.$ concentration of $353 \mathrm{ppmv}$, note that this concentration is higher than in the UM model) and the doubled $\mathrm{CO}_{2}$ run are considered (Sigmond et al., 2004). As stated in Sigmond et al. (2004), the ozone distribution is prescribed. The horizontal resolution of the ECHAM model is about $2.8^{\circ}$ (T42 horizontal resolution), and the data is interpolated to the same isentropic levels as for the UM model.

The European Centre for Medium-Range Weather Forecasts (ECMWF) ERA-interim reanalysis data on 37 pressure levels between $1000 \mathrm{hPa}$ and $1 \mathrm{hPa}$, and a horizontal resolution of $1.5^{\circ}$ is used for comparison with the model results. The monthly mean data (at 12:00 UTC) of the zonal wind and the temperature for the period 1989 to 2008 are again interpolated from isobaric to isentropic levels. Zonal averaging and averaging over the 20 years is performed to obtain a climatological dataset of $u$ and $p$ on isentropic levels, after which the isentropic potential vorticity is calculated from Eq. (1).

The relation between the potential vorticity and the zonal wind is given by the PV inversion equation, which is derived from the definition of the isentropic potential vorticity given in Eq. (1) and the conditions of hydrostatic balance and gradient wind balance between the zonal mean zonal wind, temperature and pressure. The PV inversion equation reads (see also Hinssen et al., 2010):

$$
\frac{Z_{\theta}}{g} \frac{\partial}{\partial \theta}\left(\rho \theta f_{\mathrm{loc}} \frac{\partial u}{\partial \theta}\right)+\frac{\partial^{2} u}{\partial r^{2}}+\frac{\tan \phi}{a} \frac{\partial u}{\partial r}-\frac{u}{a^{2} \cos ^{2} \phi}=\sigma \frac{\partial Z_{\theta}}{\partial r}-\frac{\partial f}{\partial r}
$$

with

$f_{\text {loc }}=f(r)+\frac{2 \tan \phi}{a} u ; r=a\left(\frac{\pi}{2}-\phi\right) ; f(r)=2 \Omega \sin \phi=2 \Omega \cos \left(\frac{r}{a}\right)$

Here, $r$ is the distance from the pole measured along the surface of the Earth, $\rho$ is the density (derived from the equation of state) and $\Omega$ is the rotation rate of the Earth.

The PV inversion equation, Eq. (4), can be seen as the formulation of thermal wind balance in terms of potential vorticity. It describes the flow pattern that is associated with a specific pattern of the potential vorticity in a balanced axisymmetric vortex centred at the pole.

The boundary condition at the pole $(r=0)$ is simply that $u=0$, because the vortex is assumed to be axi-symmetric and centred at the pole. At the outer boundary, at $10^{\circ}$, we prescribe the wind according to the circulation theorem (Hoskins et al., 1985, p 897). At the upper boundary we impose the ERA-interim wind or the modeled wind. Since we only consider inversion of the stratospheric PV distribution, zero thermal wind is imposed at the lower boundary:

$\frac{\partial u}{\partial \theta}=0$
The surface temperature distribution is strongly coupled to the PV in the lower part of the domain (below $400 \mathrm{~K}$ ), so a realistic thermal wind should be imposed at the lower boundary to obtain a realistic subtropical jet from inversion of the tropospheric PV. Zero thermal wind is, however, believed to be a reasonable boundary condition for the inversion of the stratospheric part of the PV. There is no knowledge about the wind or temperature at the surface before the inversion, and this boundary condition allows the tropospheric wind to adjust to the stratospheric PV. PV inversion is performed on the monthly PV values between $400 \mathrm{~K}$ and $1250 \mathrm{~K}$, by solving Eq. (4) by successive relaxation.

On the basis of the PV inversion equation, the zonal mean $\mathrm{PV}$ and the isentropic density are split into a reference state and an anomaly as follows:

$Z_{\theta} \equiv Z_{\theta, \text { ref }}+Z_{\theta}^{\prime} ; \sigma \equiv \sigma_{\text {ref }}+\sigma^{\prime}$

with

$Z_{\theta, \text { ref }}=\frac{f}{\sigma_{\text {ref }}}$

and

$\sigma_{\text {ref }}=\frac{\int \sigma \cos (\phi) d \phi}{\int \cos (\phi) d \phi}$

In other words, the reference isentropic density $\sigma_{\text {ref }}$ is the area-weighted average of $\sigma$ over the domain in question. In our case we choose the area poleward of $10^{\circ}$. Therefore, $\sigma_{\text {ref }}$ depends only on $\theta$. The reference PV is associated with the solution $u=0$ and $\sigma=\sigma_{\text {ref }}$, indicating that the PV anomaly represents that part of the PV field that induces a wind field, according to the PV inversion equation. With this definition two separate PV anomalies centred over the pole are distinguished: one at the tropopause and the other in the polar night stratosphere at potential temperatures above about $400 \mathrm{~K}$ (Hinssen et al., 2010). In this study, we examine the influence of the stratospheric polar cap PV anomaly between $400 \mathrm{~K}$ and $1250 \mathrm{~K}$ on the tropospheric winds, since the PV anomaly in this altitude range is most affected by $\mathrm{CO}_{2}$ doubling. It is not possible to invert just a PV anomaly with the inversion equation used here. Therefore, the PV anomalies are combined with the reference PV field. The wind fields obtained from the PV inversion will however correspond to the PV anomalies, since the reference PV alone does not induce a wind field. For the stratospheric PV inversions the stratospheric PV anomalies between 400 and $1250 \mathrm{~K}$ are thus added to the reference PV in the whole inversion domain.

The eddy heat flux is proportional to the vertical component of the Eliassen-Palm flux, which represents the vertical propagation of waves. The heat flux in the lower stratosphere $(100 \mathrm{hPa})$ is therefore often used as a measure of the wave forcing from the troposphere to the stratosphere (see also Waugh et al., 1999; Polvani and Waugh, 2004; Charlton et al., 2007). Hinssen and Ambaum (2010) further show that a quantitative relation exists between the stratospheric polar 
cap PV and the $100 \mathrm{hPa}$ eddy heat flux. About $50 \%$ of the interannual variability in the state of the Northern Hemisphere stratosphere was found to be determined by the variations in the $100 \mathrm{hPa}$ heat flux. The monthly heat flux $\left[v^{*} T^{*}\right.$ ) (a star represents a deviation from the zonal mean quantity and the brackets indicate zonal averaging) is determined from the monthly mean meridional wind $(v)$ and temperature on pressure levels for every year, for the models as well as for the ERA-interim data. In the next section, it is shown that the heat flux calculated from the monthly mean data gives a reasonable estimate of the seasonal cycle of the heat flux calculated from daily data. The area-weighted average heat flux at $100 \mathrm{hPa}$ is determined between $40^{\circ}$ and $80^{\circ}$ for both hemispheres, since most wave activity enters the stratosphere in this latitude band. The climatological flux values are determined by averaging over all years (20 years for the ERAinterim data and the ECHAM model, 25 years for the UM model).

\section{Stratospheric PV changes}

Figure 1 presents the polarcap PV anomaly, defined as the area-weighted average isentropic PV anomaly between $70^{\circ}$ and $90^{\circ}$, for the control runs (in black) and for the doubled $\mathrm{CO}_{2}$ runs (red), for both hemispheres. Throughout the remainder of this paper, we multiply the SH PV anomaly values by -1 . The polar PV anomaly is studied since the zonal wind field is related to horizontal gradients in PV (the first term on the right hand side of Eq. (4) involves the horizontal PV gradient), so that changes in the polar PV can affect the midlatitude winds. Comparison of the ERA-interim data to the model data (not shown) indicates that the model results are realistic, in amplitude as well as in seasonal cycle. Both models show a similar polarcap PV response to $\mathrm{CO}_{2}$ doubling. The Northern Hemisphere $(\mathrm{NH})$ polar stratospheric PV increases somewhat in autumn and spring due to $\mathrm{CO}_{2}$ doubling, while it decreases in winter. An increase in Southern Hemisphere ( $\mathrm{SH}$ ) polar stratospheric PV is found from autumn through spring. These PV changes are consistent with the results of Butchart et al. (2000), who find enhanced cooling in the SH stratosphere in spring, and also in the $\mathrm{NH}$ upper stratosphere in late autumn and spring, while they find a warming in the $\mathrm{NH}$ lower stratosphere in winter.

The stratospheric polarcap PV at $600 \mathrm{~K}$ is shown in Fig. 2a and $b$, for the UM model and ECHAM model, respectively. At $600 \mathrm{~K}$ the midwinter PV response is largest in the UM model. This is also true at higher levels in autumn and spring, while at higher levels the NH midwinter PV changes are somewhat larger in the ECHAM model than in the UM model (Fig. 1).

The midlatitude PV anomaly (area-weighted average PV anomaly between $35^{\circ}$ and $55^{\circ}$ ) at $600 \mathrm{~K}$ is given in Fig. $2 \mathrm{c}$ (UM model) and 2d (ECHAM model). The NH polarcap $\mathrm{PV}$ anomaly decreases in winter due to $\mathrm{CO}_{2}$ doubling, while the NH midlatitude PV anomaly increases (the amplitude of the seasonal cycle decreases in both cases), indicating increased wave breaking, mixing PV off the pole (McIntyre and Palmer, 1983, 1984). In the SH, the polarcap PV anomaly increases, and a slight decrease in the midlatitude $\mathrm{PV}$ is found throughout most of the year, with an increase in winter in the ECHAM model.

The stratospheric PV distribution is determined by radiative effects and wave effects. Since the ozone concentrations are kept fixed in the models, the PV differences between the control run and the doubled $\mathrm{CO}_{2}$ run are not related to ozone variations. The change in $\mathrm{CO}_{2}$ has a radiative effect. A higher stratospheric $\mathrm{CO}_{2}$ concentration will lead to an enhanced cooling to space (Fels et al., 1980; Butchart et al., 2000; Shindell et al., 2001). $\mathrm{CO}_{2}$ doubling will cause changes in the radiative cooling, resulting in cooling of the stratosphere that increases with height (e.g., Bell et al., 2010) and hence resulting in a change in the stability and the PV. The relation between the diabatic heating and PV is given by the PV evolution equation as given in, for example, Eq. (3) of van Delden (2003). Equation (6) in van Delden (2003) indicates that due to the strong increase of PV with height in the stratosphere (see for example Fig. 1) a decrease or weak increase of the diabatic cooling with height will lead to an increase in the PV. An increase in PV is seen in the SH (Figs. 1c and $\mathrm{d}$ and $2 \mathrm{a}$ and $\mathrm{b}$ ), and in $\mathrm{NH}$ autumn and spring, but not in $\mathrm{NH}$ winter. A more detailed study of the diabatic heating is beyond the scope of this study, but the equations in van Delden (2003) indicate that it is not trivial to say how a diabatic cooling will affect the PV, especially in a PV stratified region like the stratosphere. It would be worthwhile to investigate this in a future study, by quantifying the different terms in the PV evolution equation.

$\mathrm{CO}_{2}$ doubling can also influence the wave forcing. Eichelberger and Hartmann (2005), for example, show that an increase in the meridional temperature gradient (due to tropical upper tropospheric warming or polar lower stratospheric cooling) could lead to enhanced baroclinicity in the midlatitudes and enhanced baroclinic wave generation. An increase of the wave flux out of the troposphere could increase the Brewer-Dobson overturning circulation in the stratosphere (Butchart and Scaife, 2001; Eichelberger and Hartmann, 2005), leading to increased adiabatic warming of the polar lower stratosphere.

To examine the extent to which the wave forcing can explain the PV response, the area-weighted averaged $100 \mathrm{hPa}$ monthly eddy heat flux between $40^{\circ}$ and $80^{\circ}$ is shown in Fig. 3. Additionally, the ERA-interim $100 \mathrm{hPa}$ heat flux is given in Fig. 4. The heat flux derived from the monthly mean data is lower than the monthly averages of the heat flux derived from daily data, but the seasonal cycle is similar. This indicates that the monthly mean data might be suitable to obtain an estimate of the seasonal cycle of the heat flux. The $\mathrm{NH}$ winter heat flux is somewhat higher for the ECHAM model than for the UM model. Interestingly, this 

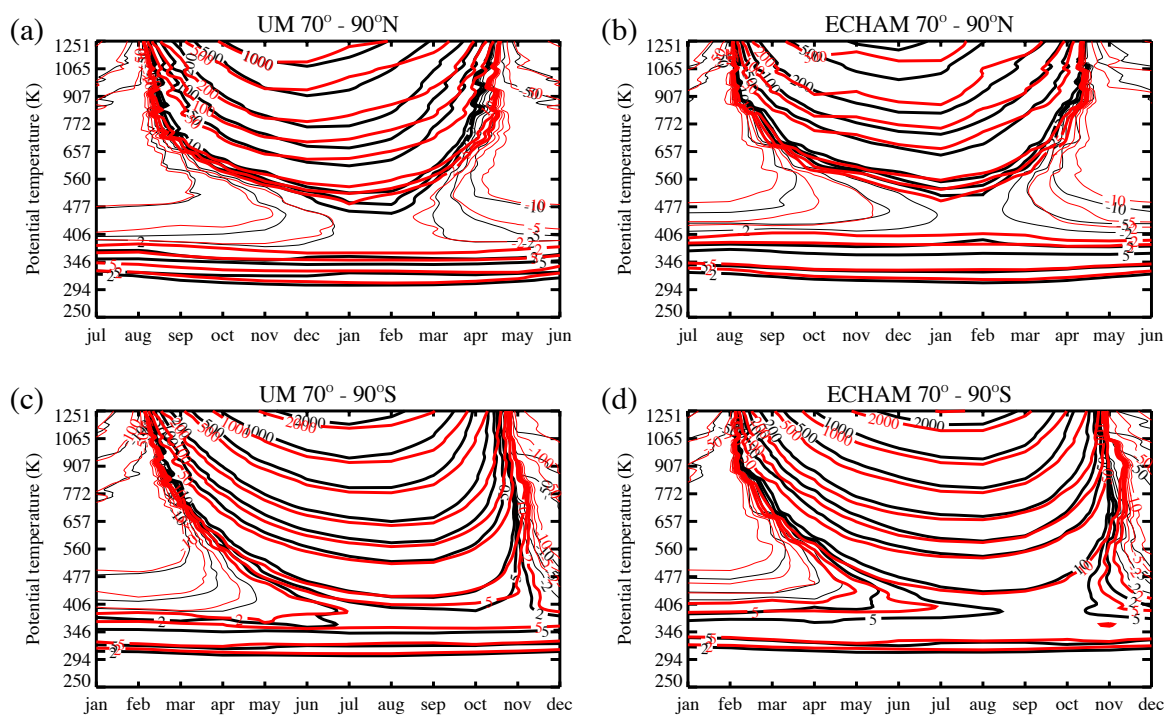

Fig. 1. Monthly climatological polarcap PV anomaly (area-weighted average between $70^{\circ}$ and $90^{\circ}$, in $\mathrm{PVU}, 1 \mathrm{PVU}^{\mathrm{N}}=10^{-6} \mathrm{~K} \mathrm{~m}^{2} \mathrm{~kg}^{-1} \mathrm{~s}^{-1}$ ) for the control run (black) and the doubled $\mathrm{CO}_{2}$ run (red), for (a) the NH UM model, (b) the NH ECHAM model, (c) minus the SH UM model and (d) minus the SH ECHAM model, as a function of time (months) and potential temperature (K). Contours at $\pm 2,5,10,50,100$, 200, 500, 1000, 2000, 3000 PVU, positive values represented by thick lines and negative values represented by thin lines. Note that for both hemispheres the horizontal axis starts in summer.

(a)

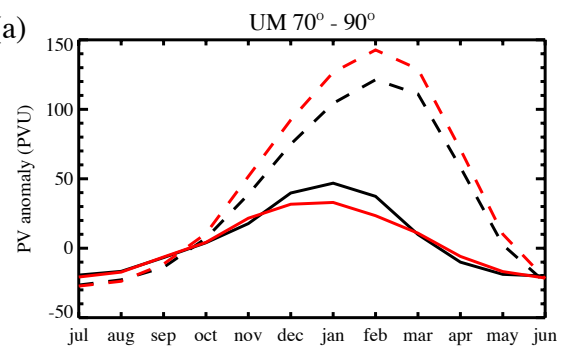

(c)

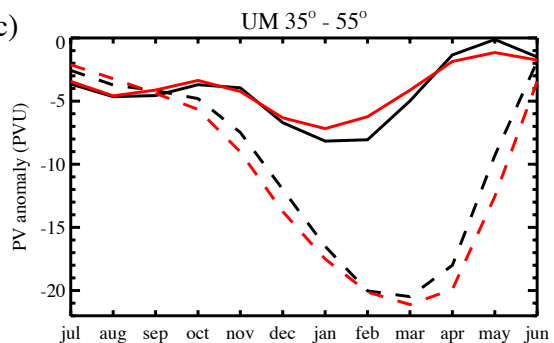

(b)

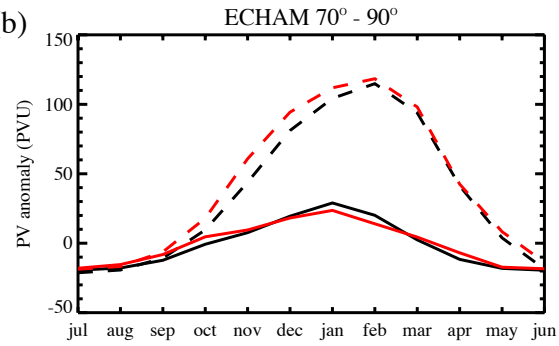

(d)

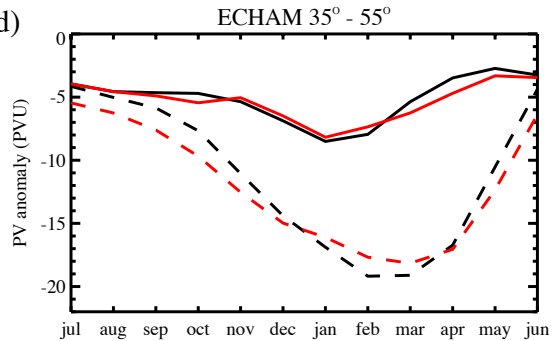

Fig. 2. Monthly climatological $600 \mathrm{~K}$ polarcap PV anomaly (PVU) for (a) the UM model and (b) the ECHAM model, and $600 \mathrm{~K}$ midlatitude PV anomaly (area-weighted average between $35^{\circ}$ and $55^{\circ}$, in PVU) for (c) the UM model and (d) the ECHAM model, for the control run (black lines) and the doubled $\mathrm{CO}_{2}$ run (red lines) for the $\mathrm{NH}$ (solid) and minus the $\mathrm{SH}$ (dashed). Months noted on the horizontal axis are for the $\mathrm{NH}$, and the $\mathrm{SH}$ values are shifted by 6 months compared to this axis.

is consistent with the ECHAM polarcap PV being somewhat lower than the UM polarcap PV. $\mathrm{CO}_{2}$ doubling hardly affects the $\mathrm{SH}$ heat flux in the UM model, and leads to a slight decrease in the SH flux in autumn and spring in the ECHAM model. The NH heat flux, on the other hand, increases in both models, especially in winter. The largest increase is found in December and January in the UM model, and in January and February in the ECHAM model. An increase in the NH 
(a)

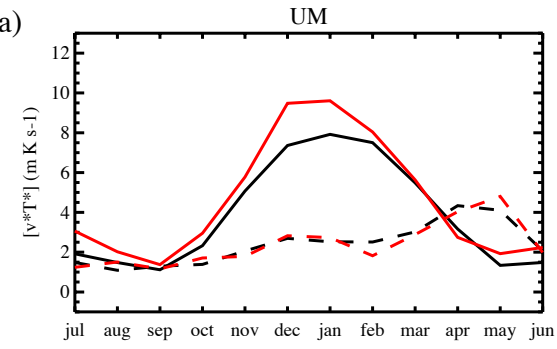

(b)

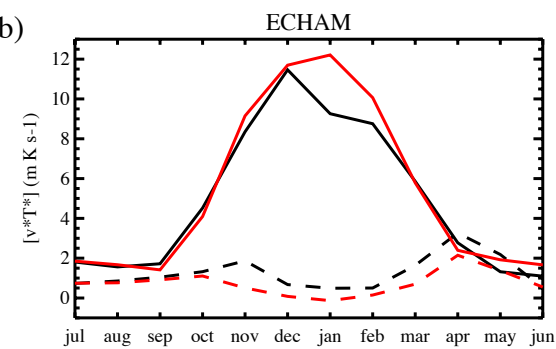

Fig. 3. Monthly climatological heat flux $\left[v^{*} T^{*}\right]$ at $100 \mathrm{hPa}$ (area-weighted average between $40^{\circ}$ and $80^{\circ}$, in $\mathrm{m} \mathrm{K} \mathrm{s}^{-1}$ ) for the control run (black lines) and for the doubled $\mathrm{CO}_{2}$ run (red lines), for the $\mathrm{NH}$ (solid) and minus $\mathrm{SH}$ (dashed), for (a) the UM model and (b) the ECHAM model, as a function of time (months). Months noted on the horizontal axis are for the $\mathrm{NH}$, and the SH values are shifted by 6 months compared to this axis.

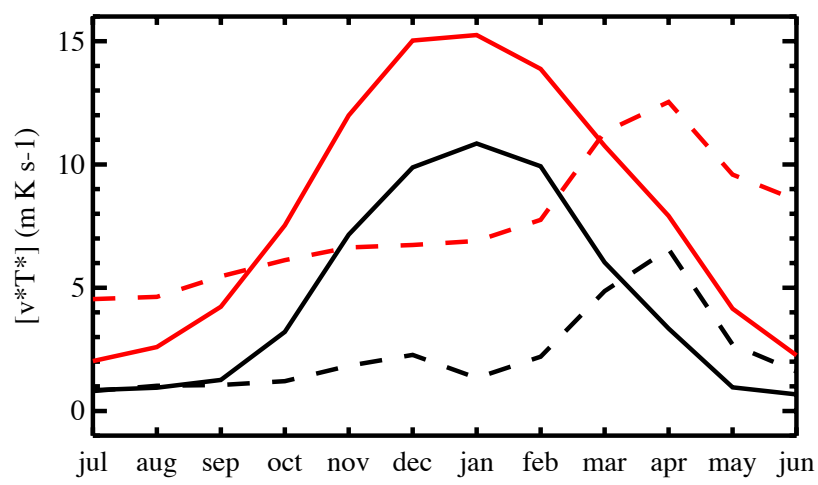

Fig. 4. ERA-interim climatological $100 \mathrm{hPa}$ heat flux, derived from monthly mean data $\left(\left[\bar{v}^{*} \bar{T}^{*}\right]\right.$, with an overbar representing the time mean, black) and monthly means of the heat flux derived from daily data $\left(\overline{\left[v^{*} T^{*}\right]}\right.$, red), for the NH (solid) and minus the SH (dashed). Months noted on the horizontal axis are for the $\mathrm{NH}$, and the $\mathrm{SH}$ values are shifted by 6 months compared to this axis.

upward flux of wave activity from the troposphere due to an increase in greenhouse gas concentrations is also found by, for example, Butchart et al. (2000), Schnadt et al. (2002) and Shepherd (2008). Haklander et al. (2008) studied changes in the NH upward wave flux in the same ECHAM model runs in more detail, and found an increase of about $12 \%$ in the January-February mean $100 \mathrm{hPa}$ heat flux due to $\mathrm{CO}_{2}$ doubling. They state that this can mainly be attributed to changes in stationary wave-1, related to an increase in the meridional temperature gradient, and suggest that at least part of the increase is due to more stationary wave- 1 generation at midlatitudes in the troposphere. Sigmond et al. (2004) show that tropospheric $\mathrm{CO}_{2}$ doubling alone results in a warming of the lower polar stratosphere in the $\mathrm{NH}$ winter. This warming is likely related to the wave forcing (through an increase in the Brewer-Dobson circulation), suggesting that the heat flux increase in the $\mathrm{NH}$ is related to the $\mathrm{CO}_{2}$ doubling in the troposphere. Changes initially made to the troposphere (increase in $\mathrm{CO}_{2}$ ) could thus affect the stratospheric PV through wave forcing. These stratospheric PV changes can again feed back on the tropospheric winds, as the troposphere adjusts to the stratospheric changes.

A stronger winter wave forcing is related to lower polarcap PV anomaly values and higher midlatitude PV anomaly values, similar to what is found for a $\mathrm{CO}_{2}$ doubling in the $\mathrm{NH}$ (Fig. 2). The increase in midlatitude winter stratospheric $\mathrm{PV}$ in the SH ECHAM model is likely related to the polar cooling and the accompanying increase in polar PV, extending further equatorward than in the control run, thereby also affecting the midlatitude PV. If this effect plays a role, it is expected to do so in late winter, when the vortex attains its maximum size at the $600 \mathrm{~K}$ level. For the ECHAM model, the decrease in midlatitude PV in autumn and spring could be related to the decrease in wave forcing (Fig. 3b), but this decrease in wave forcing is absent in the UM model, indicating that other processes must play a role as well. Other processes may incorporate changes in the propagation and absorption of waves within the stratosphere. Several studies have shown that waves tend to propagate more toward the equator for stronger westerly winds in the lower stratosphere (Hartmann et al., 2000; Shindell et al., 2001; Perlwitz and Harnik, 2003; Kushner and Polvani, 2004; Sigmond and Scinocca, 2010). Planetary wave refraction is influenced by wind shear. Waves propagating upward from the troposphere are refracted equatorward by the increased vertical wind shear in the lower stratosphere when the vortex is strong (Shindell et al., 2001). This provides a positive feedback, where a stronger vortex is less disturbed by waves. A strengthening of the $\mathrm{SH}$ vortex due to $\mathrm{CO}_{2}$ doubling might thus lead to more equatorward refraction of waves and an increase in the polarcap PV anomaly.

\section{Stratospheric influence on the troposphere}

Figures 1 and 2 displayed that a $\mathrm{CO}_{2}$ doubling affects the stratospheric PV distribution. To investigate the impact on 

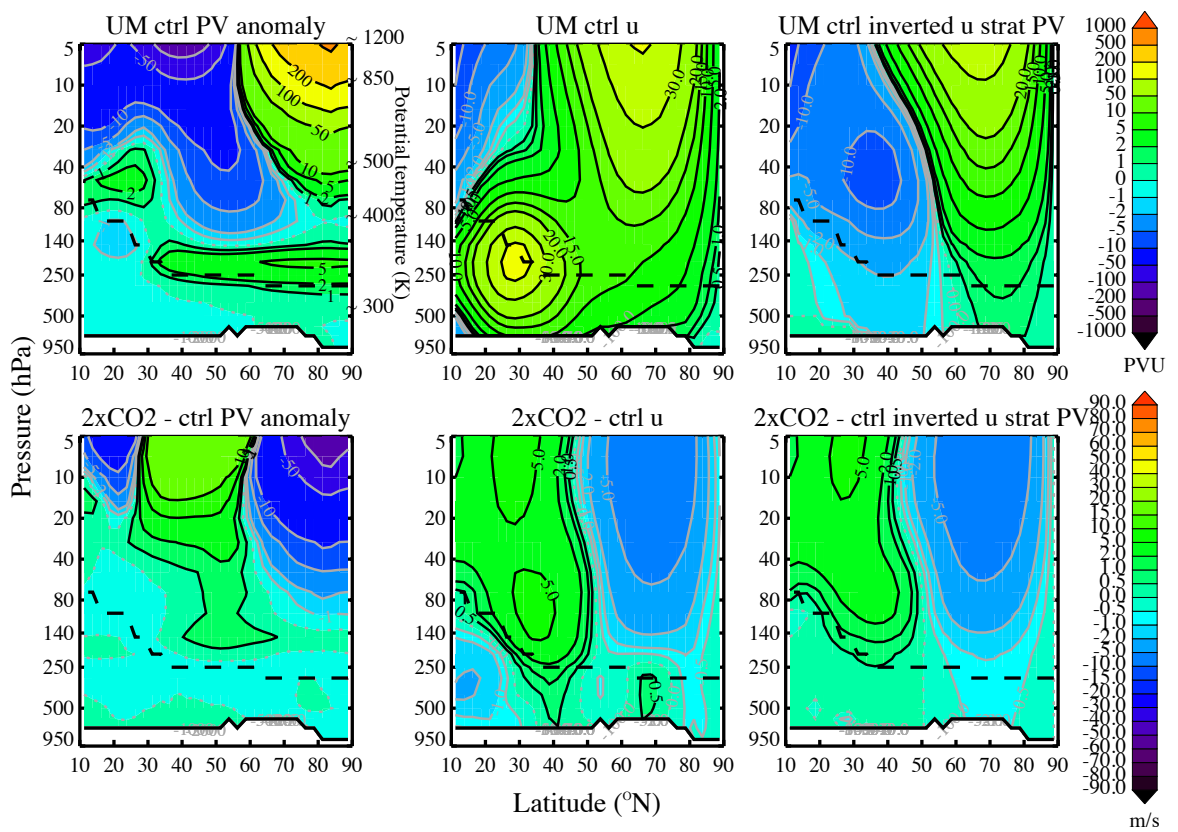

Fig. 5. February mean, zonal mean monthly PV anomaly (in PVU, left column), UM zonal wind (in $\mathrm{m} \mathrm{s}^{-1}$, middle column) and wind obtained from inverting the stratospheric PV between $400 \mathrm{~K}$ and $1250 \mathrm{~K}$ (in m s${ }^{-1}$, right column), for the UM control run (top row), and the difference between the $\mathrm{UM}$ doubled $\mathrm{CO}_{2}$ run minus the $\mathrm{UM}$ control run (bottom row), for the $\mathrm{NH}$ as a function of pressure (hPa) and latitude $\left({ }^{\circ} \mathrm{N}\right)$. The position of the control run tropopause (as measured by the 2 PVU isopleth) is indicated by the thick dashed line, while the thick solid line near the bottom of each figure represents the lower boundary of the inversion domain (interpolated back to pressure coordinates). The approximate values of the potential temperature $(\mathrm{K})$ at certain pressure levels is indicated to the right of the upper left panel. Contours for the PV anomaly are as in Fig. 1 with the zero and \pm 1 contour added, contours for the wind fields are at $\pm 0.5,1,2,5,10,15,20$ and then every $10 \mathrm{~m} \mathrm{~s}^{-1}$. Negative values are represented by grey lines and the zero contours by grey dotted lines. The upper color bar corresponds to the PV anomaly fields and the lower color bar corresponds to the wind fields.

the tropospheric circulation, PV inversion is applied to the monthly PV values between $400 \mathrm{~K}$ and $1250 \mathrm{~K}$. The formation of the polar vortex starts in the upper stratosphere in autumn, reaching the lower stratosphere in winter (Fig. 1). Since it is mainly the lower stratosphere that influences the tropospheric winds, the late winter season is examined: February in the NH and August in the SH. Since we consider climate change experiments, difficulties arise with interpreting the wind response in isentropic coordinates. Globally averaged, a tropospheric warming response of about $3 \mathrm{~K}$ is found, indicating a shift of the atmosphere relative to the potential temperature axis. As the potential temperature increases with height, the isentropic surfaces will be closer to the Earth's surface in the doubled $\mathrm{CO}_{2}$ run than in the control run. This means that the wind response in isentropic coordinates mainly shows the tropospheric vertical wind shear, and not the change in winds due to climate change. Therefore it was decided to interpolate the results back to pressure levels, to facilitate a fair comparison of the wind response in the model runs and in the inversion results. Due to the interpolations and due to the way we define the lower boundary on isentropic levels (see Sect. 2), no results are available on the lowermost pressure levels. This, however, still allows us to examine the influence of the stratosphere on the middle troposphere, which is suitable for the purpose of the present study.

Figure 5 shows the NH February mean PV anomaly and zonal mean zonal wind field for the UM control run (top row, left and middle column) and the response to $\mathrm{CO}_{2}$ doubling (lower row). The approximate variation of the potential temperature with pressure is indicated to the right of the upper left panel, where it should be noted that the potential temperature strongly varies with latitude in the troposphere, at $500 \mathrm{hPa}$ from about $280 \mathrm{~K}$ at the pole to $320 \mathrm{~K}$ in the tropics. The tropopause has a potential temperature of about $300 \mathrm{~K}$ at the pole and $380 \mathrm{~K}$ at $10^{\circ}$ in winter, so the PV anomaly above $400 \mathrm{~K}$ is indeed a stratospheric PV anomaly.

In the $\mathrm{UM}$ model, $\mathrm{CO}_{2}$ doubling results in a clear decrease in the PV anomaly over the pole, while the midlatitude PV anomaly increases. Accompanying these PV changes, a decrease in the magnitude of the westerly polar jet is found in the stratosphere. However, the wind speed on the equatorward side of the jet increases, indicating an equatorward shift of the stratospheric jet. The wind field that is obtained 

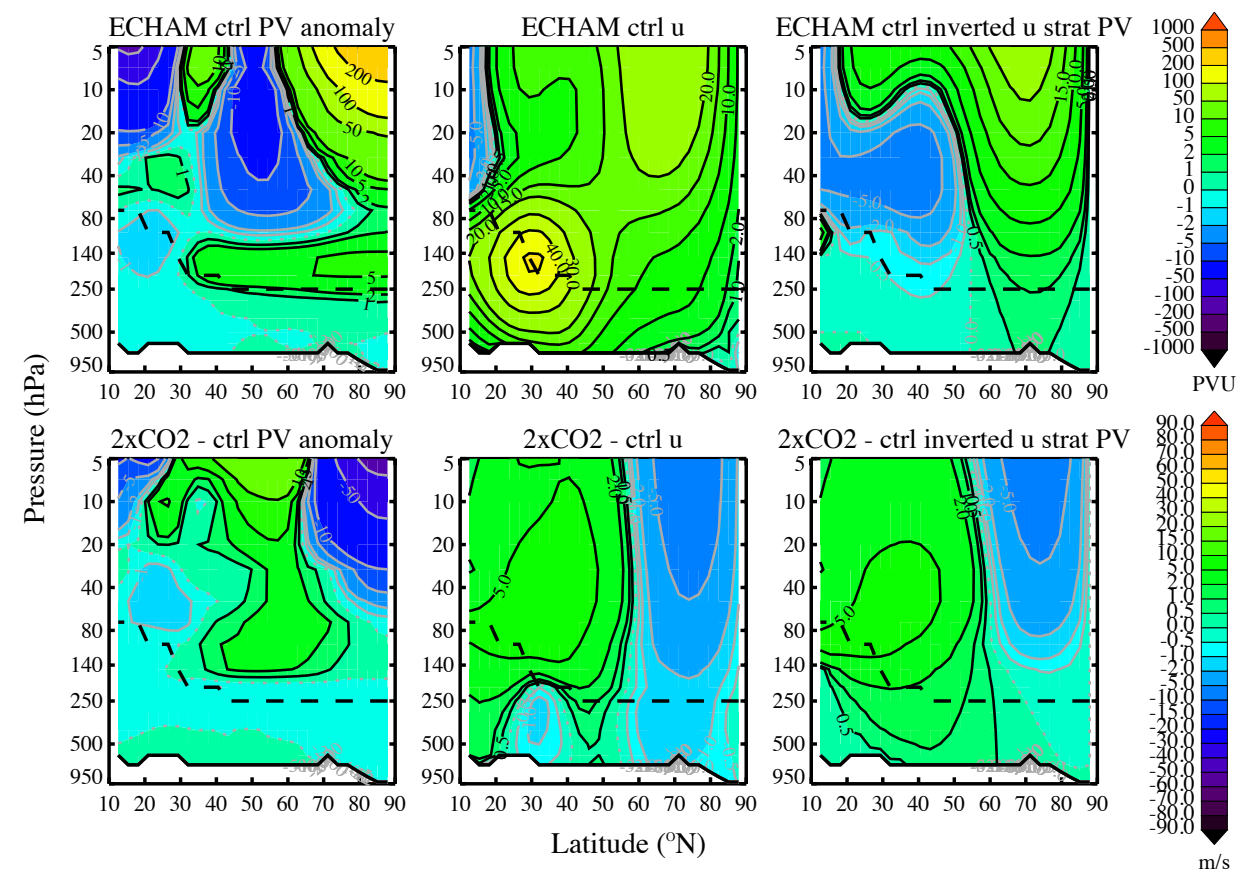

Fig. 6. Same as Fig. 5 but for the ECHAM model.
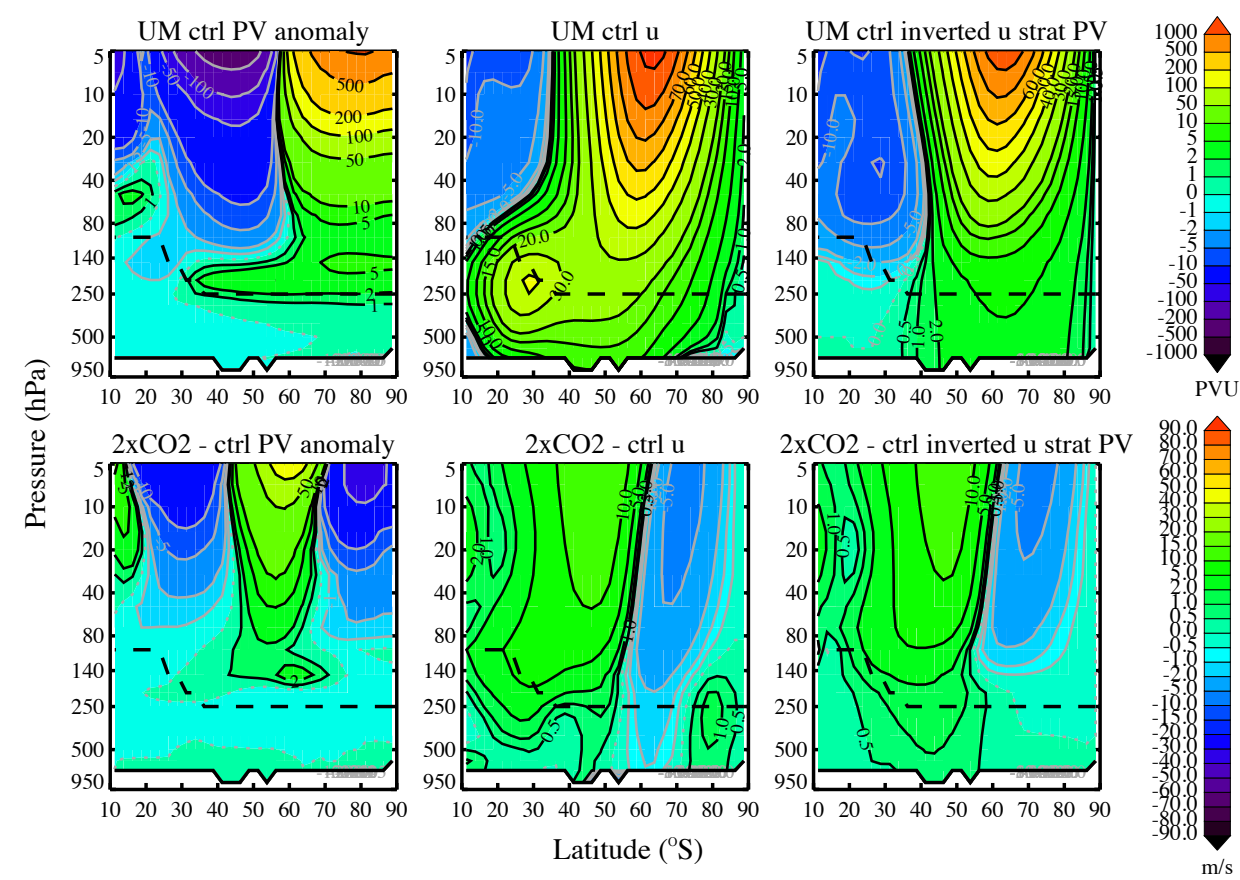

Fig. 7. Same as Fig. 5 but for August in the SH (minus the PV anomaly values are shown).

from inversion of the stratospheric $\mathrm{PV}$ above $400 \mathrm{~K}$ is shown in the right column of Fig. 5. The stratospheric PV changes induce stratospheric wind changes, but also affect the high latitude tropospheric winds (lower right panel in Fig. 5). The tropospheric wind response related to the stratospheric PV changes is small (of the order of $0.5 \mathrm{~m} \mathrm{~s}^{-1}$ ), but of the same 

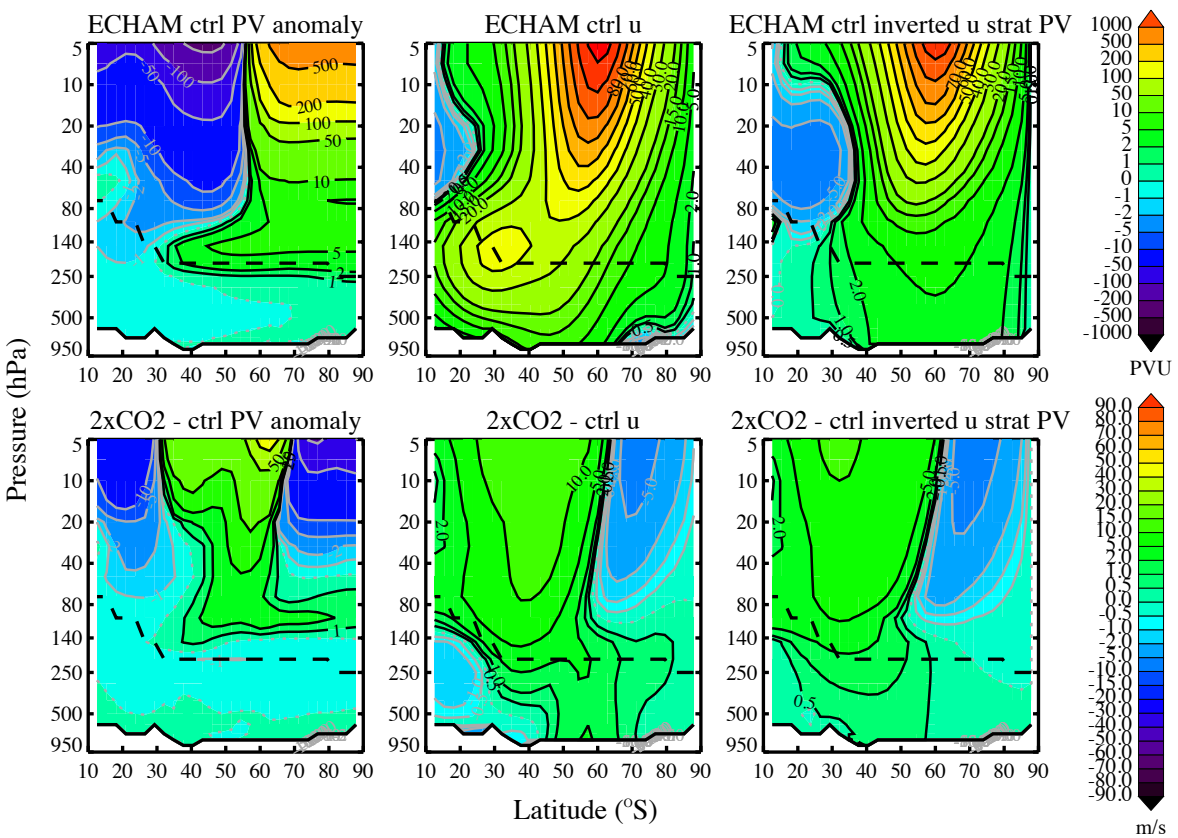

Fig. 8. Same as Fig. 6 but for August in the SH (minus the PV anomaly values are shown).

order of magnitude as the total response in model zonal wind (lower middle panel in Fig. 5). This indicates that the influence of the stratosphere is relevant for the tropospheric response, and that it results in a weaker westerly wind in the high latitude troposphere in the $\mathrm{NH}$ winter.

The results for the ECHAM model are presented in Fig. 6. The models agree on the large scale response to $\mathrm{CO}_{2}$ doubling. Both show a decrease in the polar stratospheric PV, a decrease in the high latitude winds and an equatorward shift of the stratospheric polar jet. However, for the ECHAM model, the decrease in westerly winds in the stratospheric inversions is restricted to the higher latitude stratosphere (lower right panel in Fig. 6), while an increased westerly influence (of 0.5 to $1 \mathrm{~m} \mathrm{~s}^{-1}$ ) of the stratosphere on the midlatitude tropospheric winds is found. The expression "westerly influence" on the tropospheric winds is used here to indicate that the tropospheric winds will be more westerly than without this influence (this can mean stronger westerlies or a switch from easterlies to westerlies). Decreased PV anomaly values are indeed restricted to somewhat higher latitudes and levels in the ECHAM model than in the UM model, while an increase in the mid- to high latitude PV anomaly is found in the lower stratosphere in the ECHAM model (compare the lower left panels of Figs. 5 and 6). These figures illustrate that a slight shift in the location of a PV anomaly (in altitude or latitude) can change the tropospheric response to stratospheric PV changes.

The SH August mean PV anomaly, wind field and inverted wind field from the stratospheric PV are shown in Figs. 7 and 8 for the UM model and the ECHAM model, respectively.
Similar to Fig. 5, results are presented for the control run and the difference between doubled $\mathrm{CO}_{2}$ run and the control run. In the SH, both models show an increase in the stratospheric PV anomaly around $55^{\circ}$, while the low latitude and polar PV anomaly values decrease. In both models the stratospheric PV differences have a westerly influence on the midlatitude tropospheric winds (lower right panel in Figs. 7 and 8). The tropospheric influence is of the same order as in the NH in the ECHAM model, but a larger increase of the middle stratospheric jet is found in the SH. Similar to the $\mathrm{NH}$, an equatorward shift of the polar jet is also seen in the SH response.

It should be noted that the PV anomalies shown in Figs. 5 to 8 are the isentropic PV values interpolated to pressure coordinates. In general the same features are observed in both coordinate systems, but an exception is the polar stratospheric $\mathrm{PV}$ anomaly in the $\mathrm{SH}$, which shows a decrease due to $\mathrm{CO}_{2}$ doubling on pressure levels in August (Figs. 7 and 8), while an increase was observed on isentropic levels (Fig. 2a and $b$ ). This is related to a decrease in pressure on isentropic levels over the south pole due to $\mathrm{CO}_{2}$ doubling, while $\mathrm{CO}_{2}$ doubling hardly affects the pressure over the north pole (in February at $600 \mathrm{~K}$ ). The stratospheric polar PV response in the $\mathrm{NH}$ is therefore similar on pressure levels and on isentropic levels.

In the previous section, the interpretation of the PV response to $\mathrm{CO}_{2}$ doubling was given on isentropic levels, since we consider the isentropic PV. It should however be kept in mind that the interpretation of a response to climate change depends on the coordinate system that is used. 
(a)

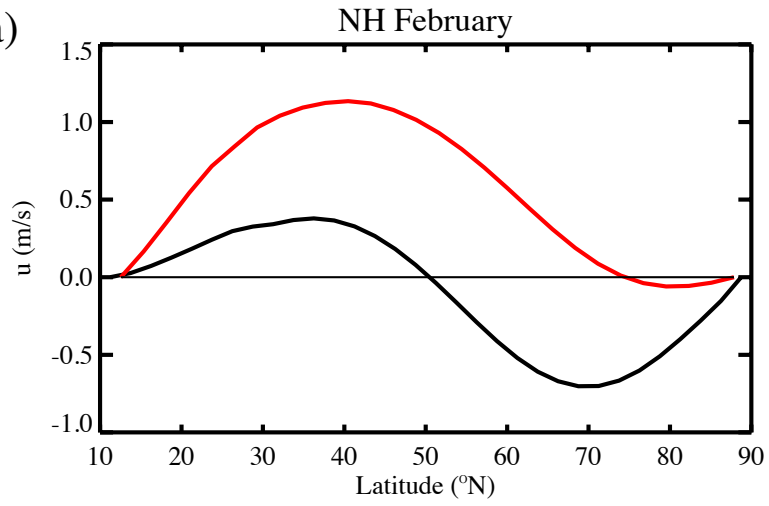

(b)

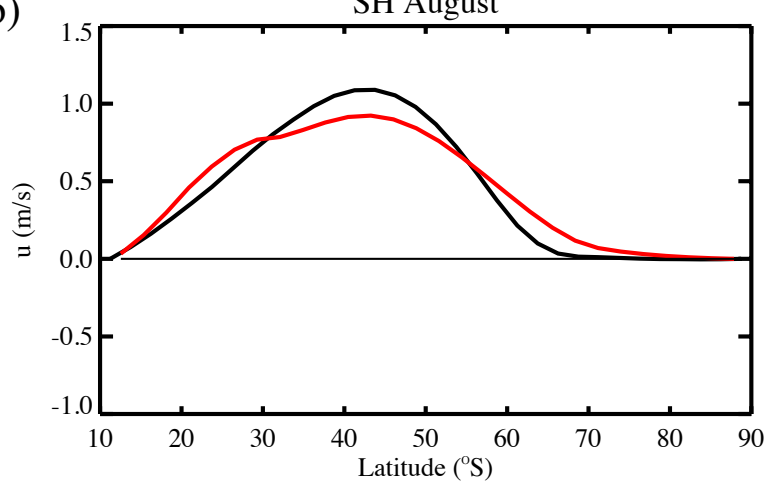

Fig. 9. Zonal mean zonal wind response to $\mathrm{CO}_{2}$ doubling (doubled $\mathrm{CO}_{2}$ run minus the control run), obtained from inverting the stratospheric PV between $400 \mathrm{~K}$ and $1250 \mathrm{~K}_{\text {(in m s}}{ }^{-1}$ for the UM model (black lines) and the ECHAM model (red lines) at $400 \mathrm{hPa}$ as a function of latitude, for (a) February in the NH and (b) August in the SH.

The tropospheric response related to changes in the stratospheric PV is summarized in Fig. 9, which shows the wind response in the middle troposphere, at $400 \mathrm{hPa}$, for February in the NH (Fig. 9a) and for August in the SH (Fig. 9b). In the UM model, there is an easterly response on the tropospheric winds north of $50^{\circ} \mathrm{N}$, while the response is westerly at low northern latitudes. The ECHAM model gives a westerly response south of $70^{\circ} \mathrm{N}$ and hardly any response at the high northern latitudes. In the SH, both models give a similar westerly response equatorward of about $65^{\circ} \mathrm{S}$, maximizing at $1 \mathrm{~m} \mathrm{~s}^{-1}$ around $40^{\circ} \mathrm{S}$.

The previous results were for the late winter season. Figure 10 indicates how the wind response, obtained from inverting the stratospheric $\mathrm{PV}$, changes throughout the year, as a function of pressure, at $71^{\circ}$.

In the UM model, the $\mathrm{NH}$ tropospheric wind response to the stratospheric PV changes is small throughout the year, with a slightly decreased westerly influence in late winter and a slightly increased westerly influence in summer. For the $\mathrm{NH}$ response in the ECHAM model, $\mathrm{CO}_{2}$ doubling increases the westerly influence of the stratosphere on the high latitude tropospheric winds from summer to early winter and in early spring, while a decreased westerly influence is found in late winter.

A slight decrease in the westerly influence is found in the winter season in the $\mathrm{SH}$ as well. The $\mathrm{SH}$ response to $\mathrm{CO}_{2}$ doubling is an increased westerly influence of the stratosphere on the midlatitude tropospheric winds of the order of 0.5 to $1 \mathrm{~m} \mathrm{~s}^{-1}$ throughout the year (not shown), but at the high latitudes this increased westerly influence is restricted to the summer and autumn seasons (Fig. 10c and d).

For comparison, Fig. 11 shows the total wind response in the model runs, again at $71^{\circ}$. The figures presented in this section show that the tropospheric wind response due to changes in the stratospheric PV is small, of the order of 0.5 to $1 \mathrm{~m} \mathrm{~s}^{-1}$, but also indicate that the total wind response in the model is of the same order of magnitude. The stratospheric influence is therefore not negligible. The tropospheric response in the models is sometimes of opposite sign as the response to stratospheric PV changes, indicating that tropospheric processes can modify and mask the stratospheric influence.

\section{Conclusions}

We examined the influence of a $\mathrm{CO}_{2}$ doubling on the zonal mean stratospheric PV distribution for the UM model (the 64-level Hadley Centre Atmosphere Model coupled to a thermodynamic slab ocean model) and the middle-atmosphere version of the ECHAM4 climate model. Subsequently, we investigated the tropospheric wind response to changes in the stratospheric PV, by inverting the stratospheric PV.

An increase in greenhouse gases enhances the stratospheric emission of longwave radiation and the cooling to space, which could lead to an increase in the stratospheric PV (similar to what is observed during the polar night when the polar stratosphere cools). This increase in PV is indeed found in the $\mathrm{SH}$ winter, but not in the $\mathrm{NH}$, indicating that other processes are of importance as well. Inspection of the $100 \mathrm{hPa}$ eddy heat flux, used as a measure of the wave forcing from the troposphere to the stratosphere, shows an increased winter flux in the $\mathrm{NH}$ due to $\mathrm{CO}_{2}$ doubling. The $\mathrm{PV}$ response might be coupled to the change in the heat flux, where an increased heat flux is associated with a reduced polarcap PV anomaly and an enhanced midlatitude PV anomaly, consistent with the PV-flux relation found by Hinssen and Ambaum (2010) for the interannual variability in stratospheric PV. In autumn and spring the change in heat flux is small and the $\mathrm{NH}$ polar PV slightly increases, likely related to the cooling effect of the increased $\mathrm{CO}_{2}$ concentrations. In the $\mathrm{SH}, \mathrm{CO}_{2}$ doubling hardly affects the $100 \mathrm{hPa}$ heat flux, and the radiative effect seems to dominate, leading to an increase in the polar PV on isentropic levels. Further study in line with the work of Hinssen and Ambaum (2010) is, however, needed to examine the relation between the stratospheric PV and heat 

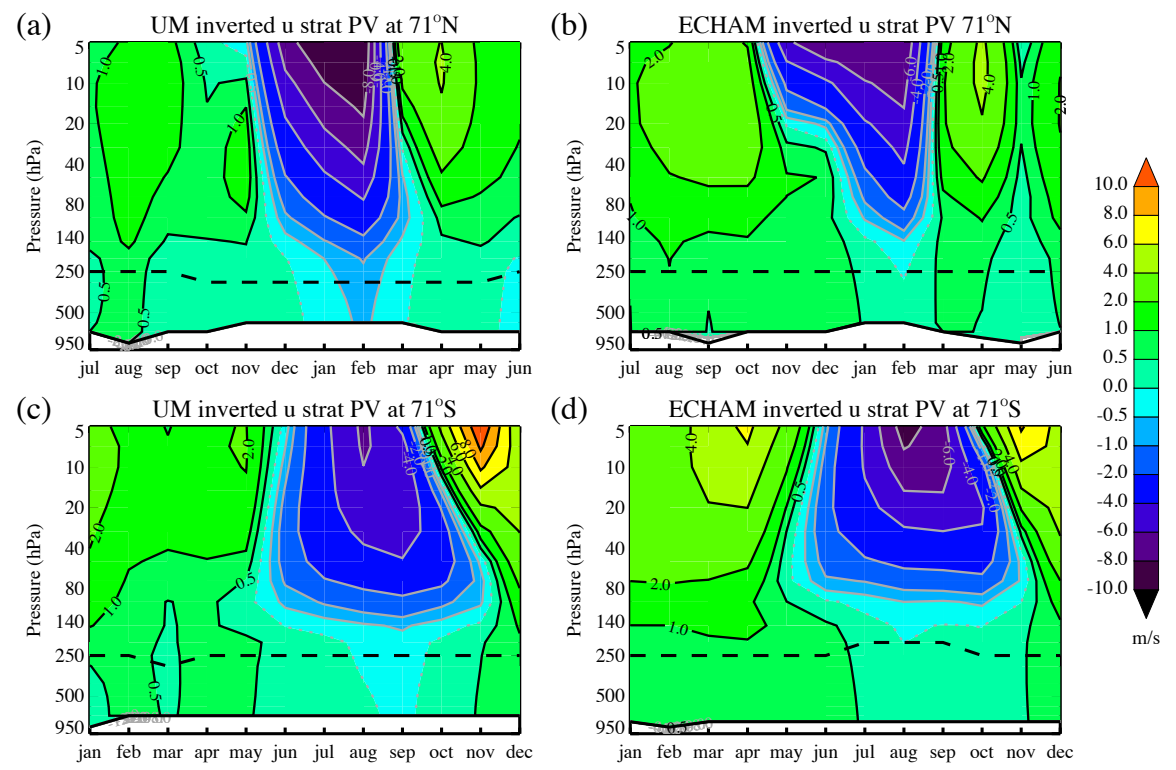

Fig. 10. Monthly zonal mean zonal wind response to $\mathrm{CO}_{2}$ doubling, obtained from inverting the stratospheric $\mathrm{PV}$ between $400 \mathrm{~K}$ and $1250 \mathrm{~K}$ (in $\mathrm{m} \mathrm{s}^{-1}$ ), (a) at $71^{\circ} \mathrm{N}$ for the UM model, (b) at $71^{\circ} \mathrm{N}$ for the ECHAM model, (c) at $71^{\circ} \mathrm{S}$ for the UM model, and (d) at $71^{\circ} \mathrm{S}$ for the ECHAM model, as a function of time and pressure. Contours every $2 \mathrm{~m} \mathrm{~s}^{-1}$ with the \pm 0.5 and $1 \mathrm{~m} \mathrm{~s}^{-1}$ contours added. Negative values are represented by grey lines and the zero contours by grey dotted lines.
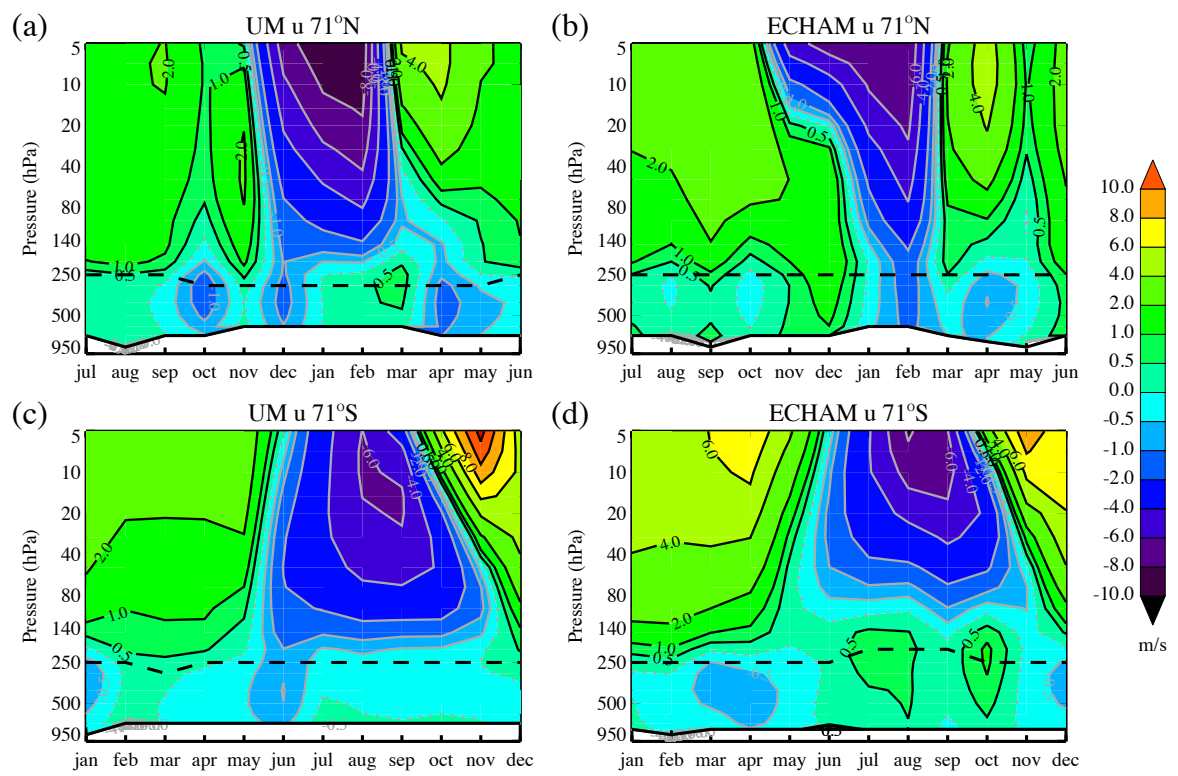

Fig. 11. Same as Fig. 10 but for the model wind response.

flux under climate change in more detail. This could give more certainty about the influence of changes in the heat flux on the stratospheric PV for the different hemispheres and different seasons. Timestep output from the models would be needed for such a study. Furthermore, it would be interesting to investigate whether the use of timestep output from the models instead of monthly mean values affects the results presented here. 
The influence of the stratospheric PV on the tropospheric wind depends on the PV in the lower stratosphere. Due to $\mathrm{CO}_{2}$ doubling, the $\mathrm{SH}$ lower stratospheric PV increases in late winter. An increased westerly influence of the stratosphere on the tropospheric midlatitude winds is therefore found in August, in both models. The largest PV increases are found in midlatitudes, at the edge of the vortex. The horizontal gradient in PV thus increases in the midlatitudes, leading to increased westerlies, but the horizontal PV gradient decreases at high latitudes, leading to somewhat decreased westerlies there, mainly in the stratosphere. In the $\mathrm{NH}, \mathrm{CO}_{2}$ doubling is associated with a decrease in the stratospheric PV in late winter, resulting in a reduced westerly influence of the stratospheric PV on the high latitude tropospheric winds. In the ECHAM model, the decrease in stratospheric PV is, however, restricted to higher altitudes than in the UM model, and an increased westerly influence is found in the low to midlatitudes, related to the increase in midlatitude PV in the lower stratosphere.

The tropospheric response in zonal wind due to stratospheric PV changes is of the order of 0.5 to $1 \mathrm{~m} \mathrm{~s}^{-1}$. The tropospheric wind response obtained from the stratospheric inversions differs in structure from the total tropospheric wind response, but is of similar magnitude. This indicates that changes in the stratosphere can certainly modify the tropospheric wind response to $\mathrm{CO}_{2}$ doubling, but that they can not explain the total tropospheric response to $\mathrm{CO}_{2}$ doubling. It can, however, be important to involve the stratosphere in climate studies, since the present study shows that changes in the stratosphere can modify the wind response in the troposphere.

Although radiative effects of greenhouse gases are important in determining the stratospheric PV distribution, it can not simply be assumed that the stratospheric PV increases with increasing greenhouse gas concentrations, since the wave forcing of the stratosphere might also change due to increases in $\mathrm{CO}_{2}$. The results presented here, combined with the findings of Hinssen and Ambaum (2010), indicate that, in the $\mathrm{NH}$, the wave effect might play an important role and lead to a decrease in the polar stratospheric PV anomaly. Further research (possibly in line with the work of Hinssen and Ambaum, 2010) is needed to clarify to what extent the stratospheric PV changes might be related to the changes in wave forcing. The influence of the stratosphere on the tropospheric response to climate change depends very sensitive on the radiatively and dynamically induced PV changes in the lower stratosphere. This is consistent with the studies of Sigmond et al. (2008) and Sigmond and Scinocca (2010), who found that the state of the lower stratosphere influences the tropospheric response to climate change, and that a low model top, in the middle stratosphere, is sufficient to capture the stratospheric influence.
Acknowledgements. The ECMWF ERA-interim data used in this study have been provided by ECMWF. The ECHAM model data were made available by Alwin Haklander at KNMI, and Michael Sigmond at the University of Toronto. We thank Theo Opsteegh and Aarnout van Delden for useful discussions.

Edited by: M. Dameris

\section{References}

Baldwin, M. P., Dameris, M., and Shepherd, T. G.: How will the stratosphere affect climate change?, Science, 316, 1576-1577, 2007.

Bell, C. J., Gray, L. J., and Kettleborough, J.: Changes in Northern Hemisphere stratospheric variability under increased $\mathrm{CO}_{2}$ concentrations, Q. J. Roy. Meteor. Soc., 136, 1181-1190, 2010.

Black, R. X.: Stratospheric forcing of surface climate in the Arctic Oscillation, J. Climate, 15, 268-277, 2002.

Black, R. X. and McDaniel, B. A.: Diagnostic case studies of the Northern Annular Mode, J. Climate, 17, 3990-4004, 2004.

Butchart, N. and Scaife, A. A.: Removal of chlorofluorocarbons by increased mass exchange between the stratosphere and troposphere in a changing climate, Nature, 410, 799-802, 2001.

Butchart, N., Austin, J., Knight, J. R., Scaife, A. A., and Gallani, M. L.: The response of the stratospheric climate to projected changes in the concentrations of well-mixed greenhouse gases from 1992 to 2051, J. Climate, 13, 2142-2159, 2000.

Charlton, A. J., Polvani, L. M., Perlwitz, J., Sassi, F., Manzini, E., Shibata, K., Pawson, S., Nielsen, J. E., and Rind, D.: A new look at stratospheric sudden warmings. Part II: Evaluation of numerical model simulations, J. Climate, 20, 470-488, 2007.

Davis, C. A.: Piecewise potential vorticity inversion, J. Atmos. Sci., 49, 1397-1411, 1992.

Edouard, S., Vautard, R., and Brunet, G.: On the maintenance of potential vorticity in isentropic coordinates, Q. J. Roy. Meteor. Soc., 123, 2069-2094, 1997.

Eichelberger, S. J. and Hartmann, D. L.: Changes in the strength of the Brewer-Dobson circulation in a simple AGCM, Geophys. Res. Lett., 32, L15807, doi:10.1029/2005GL022924, 2005.

Fels, S. B., Mahlman, J. D., Schwarzkopf, M. D., and Sinclair, R. W.: Stratospheric sensitivity to perturbations in ozone and carbon dioxide: Radiative and dynamical response, J. Atmos. Sci., 37, 2265-2297, 1980.

Gillett, N. P., Allen, M. R., McDonald, R. E., Senior, C. A., Shindell, D. T., and Schmidt, G. A.: How linear is the Arctic Oscillation response to greenhouse gases?, J. Geophys. Res., 107, D3, doi:10.1029/2001JD000589, 2002.

Gillett, N. P., Allen, M. R., and Williams, K. D.: Modelling the atmospheric response to doubled $\mathrm{CO}_{2}$ and depleted stratospheric ozone using a stratosphere-resolving coupled GCM, Q. J. Roy. Meteor. Soc., 129, 947-966, doi:10.1256/qj.02.102, 2003.

Haklander, A. J., Siegmund, P. C., Sigmond, M., and Kelder, H. M.: How does the northern-winter wave driving of the Brewer-Dobson circulation increase in an enhanced$\mathrm{CO}_{2}$ climate simulation?, Geophys. Res. Lett., 35, L07702, doi:10.1029/2007GL033054, 2008.

Hartley, D. E., Villarin, J. T., Black, R. X., and Davis, C. A.: A new perspective on the dynamical link between the stratosphere and 
troposphere, Nature, 391, 471-474, 1998.

Hartmann, D. L., Wallace, J. M., Limpasuvan, V., Thompson, D. W. J., and Holton, J. R.: Can ozone depletion and global warming interact to produce rapid climate change?, P. Natl. Acad. Sci. USA, 97, 1412-1417, 2000.

Haynes, P.: Stratospheric dynamics, Annual Review of Fluid Mechanics, 37, 263-293, doi:10.1146/annurev.fluid.37.061903.175710, 2005.

Haynes, P. H., Marks, C. J., McIntyre, M. E., Shepherd, T. G., and Shine, K. P.: On the "downward control" of extratropical diabatic circulations by eddy-induced mean zonal forces, J. Atmos. Sci., 48, 651-678, 1991.

Hinssen, Y. B. L. and Ambaum, M. H. P.: Relation between the 100-hPa heat flux and stratospheric potential vorticity, J. Atmos. Sci., 67, 4017-4027, 2010.

Hinssen, Y., van Delden, A., Opsteegh, T., and de Geus, W.: Stratospheric impact on tropospheric winds deduced from potential vorticity inversion in relation to the Arctic Oscillation, Q. J. Roy. Meteor. Soc., 136, 20-29, doi:10.1002/qj.542, 2010.

Hoskins, B. J., McIntyre, M. E., and Robertson, A. W.: On the use and significance of isentropic potential vorticity maps, Q. J. Roy. Meteor. Soc., 111, 877-946, 1985.

Kleinschmidt, E.: Über aufbau und entstehung von zyklonen, Meteorol. Rundsch., 3, 1-6, 1950.

Kushner, P. J. and Polvani, L. M.: Stratosphere-troposphere coupling in a relatively simple AGCM: The role of eddies, J. Climate, 17, 629-639, 2004.

McIntyre, M. E. and Palmer, T. N.: Breaking planetary waves in the stratosphere, Nature, 305, 593-600, 1983.

McIntyre, M. E. and Palmer, T. N.: The "surf zone" in the stratosphere, J. Atmos. Terr. Phys., 46, 825-849, 1984.

Moritz, R. E., Bitz, C. M., and Steig, E. J.: Dynamics of recent climate change in the Arctic, Science, 297, 1497-1502, 2002.

Perlwitz, J. and Harnik, N.: Observational evidence of a stratospheric influence on the troposphere by planetary wave reflection, J. Climate, 16, 3011-3026, 2003.
Polvani, L. M. and Waugh, D. W.: Upward wave activity flux as a precursor to extreme stratospheric events and subsequent anomalous surface weather regimes, J. Climate, 17, 3548-3554, 2004.

Schnadt, C., Dameris, M., Ponater, M., Hein, R., Grewe, V., and Steil, B.: Interaction of atmospheric chemistry and climate and its impact on stratospheric ozone, Clim. Dynam., 18, 501-517, 2002.

Shepherd, T. G.: Dynamics, stratospheric ozone, and climate change, Atmos. Ocean, 46, 117-138, doi:10.3137/ao.460106, 2008.

Shindell, D. T., Miller, R. L., Schmidt, G. A., and Pandolfo, L.: Simulation of recent northern winter climate trends by greenhouse-gas forcing, Nature, 399, 452-455, 1999.

Shindell, D. T., Schmidt, G. A., Miller, R. L., and Rind, D. Northern Hemisphere winter climate response to greenhouse gas, ozone, solar, and volcanic forcing, J. Geophys. Res., 106, 7193 7210, 2001.

Sigmond, M. and Scinocca, J. F.: The influence of the basic state on the northern hemisphere circulation response to climate change, J. Climate, 23, 1434-1446, doi:10.1175/2009JCLI3167.1, 2010.

Sigmond, M., Siegmund, P. C., Manzini, E., and Kelder, H.: A simulation of the separate climate effects of middle-atmospheric and tropospheric $\mathrm{CO}_{2}$ doubling, J. Climate, 17, 2352-2367, 2004.

Sigmond, M., Scinocca, J. F., and Kushner, P. J.: Impact of the stratosphere on tropospheric climate change, Geophys. Res. Lett., 35, L12706, doi:10.1029/2008GL033573, 2008.

Thompson, D. W. J., Furtado, J. C., and Shepherd, T. G.: On the tropospheric response to anomalous stratospheric wave drag and radiative heating, J. Atmos. Sci., 63, 2616-2629, 2006.

van Delden, A.: Adjustment to heating, potential vorticity and cyclogenesis, Q. J. Roy. Meteor. Soc., 129, 3305-3322, 2003.

Waugh, D. W., Randel, W. J., Pawson, S., Newman, P. A., and Nash, E. R.: Persistence of the lower stratospheric polar vortices, J. Geophys. Res., 104, 27191-27201, 1999. 